\title{
Weathering-limited hillslope evolution in carbonate landscapes
}

\author{
Vincent Godard ${ }^{1, *}$, Vincent Ollivier ${ }^{2}$, Olivier Bellier ${ }^{1}$, Cécile Miramont ${ }^{3}$, \\ Esmaeil Shabanian ${ }^{1, \dagger}$, Jules Fleury ${ }^{1}$, Lucilla Benedetti ${ }^{1}$, Valéry Guillou ${ }^{1}$, \\ and ASTER Team ${ }^{1, \#}$ \\ ${ }^{1}$ Aix-Marseille Université, CNRS, IRD, CDF, CEREGE UM34, 13545 Aix-en-Provence, France \\ ${ }^{2}$ Aix Marseille Université, CNRS, MCC, LAMPEA UMR 7269, 13094 Aix-en-Provence, France \\ ${ }^{3}$ Aix-Marseille Université, CNRS, IRD, Avignon Université, IMBE UMR 7263, 13545 Aix-en-Provence, \\ France \\ *Corresponding author : godard@cerege.fr \\ ${ }^{\dagger}$ Now at : Institute for Advanced Studies in Basic Sciences, Gava Zang - Zanjan, Iran \\ \# Maurice Arnold, Georges Aumaître, Didier L. Bourlès, Karim Keddadouche
}

Published as: Godard, V., Ollivier, V., Bellier, O., Miramont, C., Shabanian, E., Fleury, J., Benedetti, L., Guillou, V., ASTER, T., 2016. Weatheringlimited hillslope evolution in carbonate landscapes. Earth Planet. Sci. Lett. 446, 10-20. https://doi.org/10.1016/j.epsl.2016.04.017

\begin{abstract}
Understanding topographic evolution requires integrating elementary processes acting at the hillslope scale into the long-wavelength framework of landscape dynamics. Recent progress has been made in the quantification of denudation of eroding landscapes and its links with topography. Despite these advances, data is still sparse in carbonate terrain, which covers a significant part of the Earth's surface. In this study, we measured both long-term denudation rates using in situ-produced ${ }^{36} \mathrm{Cl}$ concentrations in bedrock and regolith clasts and surface convexity at 12 sites along ridges of the Luberon carbonate range in Provence, Southeastern France. Starting from $\sim 30 \mathrm{~mm} / \mathrm{ka}$ for the lowering of the summit plateau surface, denudation linearly increases with increasing hilltop convexity up to $\sim 70 \mathrm{~mm} / \mathrm{ka}$, as predicted by diffusive mass transport theory. Beyond this point denudation rates appear to be insensitive to the increase in hilltop convexity. We interpret this constant denudation as indicating a transition from a regime where hillslope evolution is primarily controlled by diffusive downslope regolith transport, toward a situation in which denudation is limited by the rate at which physical and chemical weathering processes can produce clasts and lower the hilltop. Such an abrupt transition into a weathering-limited dynamics may prevent hillslope
\end{abstract}


denudation from balancing the rate of base level fall imposed by the river network and could potentially explain the development of high local relief in many Mediterranean carbonate landscapes.

Keywords Landscape evolution; Carbonates; Denudation; Cosmogenic nuclides; Hillslope processes

\section{Introduction}

Our understanding of landscape dynamics relies on the ability to predict rates of denudation from the measurement of topographic properties. The possibility of establishing a causal link between the two has been greatly enhanced over the last two decades, mainly due to several critical methodological breakthroughs. First, the availability of high resolution representations of the topographic surface, through LiDAR or photogrammetric techniques, has allowed the systematic measurement of elevation over length-scales that are relevant for the elementary geomorphic processes at work, in particular across hillslopes [e.g. Roering et al., 1999; Perron et al., 2008]. Second, we can now measure in situ-produced cosmogenic nuclides concentrations in various near-surface materials, allowing accurate quantification of the rates of geomorphic processes. The combination of these spatial and temporal constraints has allowed the investigation and validation of several Geomorphic Transport Laws [Dietrich et al., 2003] pertaining to first-order open questions in landscape evolution [e.g. Small et al., 1999; Roering et al., 2007; Hurst et al., 2012; Johnstone and Hilley, 2015; Foster et al., 2015]. For example, based on a simple conceptual model for the evolution of soil-mantled hillslopes [Gilbert, 1909; Culling, 1960], field observations of diagnostic relationships between landscape morphology (slope angles, curvature) and rates of evolution (downslope regolith transport, denudation) are direct hints of the occurrence of specific processes [e.g. McKean et al., 1993; Heimsath et al., 1997; Anderson, 2002; Hurst et al., 2012].

Many of the aforementioned studies have focused on the evolution of landscapes developed on quartz-rich lithologies, where the measurement of in situ-produced ${ }^{10} \mathrm{Be}$ concentrations in bedrock or regolith materials provided direct constraints on processes timescales. Recent advances on the calibration of ${ }^{36} \mathrm{Cl}$ production rate from Ca spallation have opened the way for the implementation of similar approaches in carbonate landscapes [Stone et al., 1994; Schimmelpfennig et al., 2009]. For example, Ryb et al. [2013, 2014b,a] have provided important insights into the spatial distribution of denudation for carbonate dominated landscapes across a strong climatic gradient in Israel. 
The significant control of the precipitation gradient on the denudation pattern support the idea that dissolution is the major regulator of the evolution of such landscapes and that physical processes play only a secondary role, unless water availability becomes limiting for chemical weathering. However, in many carbonate landscapes hillslopes display convex hilltops that are commonly associated with diffusion-like regolith transport [Gilbert, 1909; Culling, 1960]. These observations suggest that physical weathering and regolith transport may play a significant role in the evolution of carbonate hillslopes in addition to total dissolution. Due to their frequent occurrence, especially in Peri-Mediterranean regions, it is of major interest to understand the dynamics of carbonates dominated landscapes, in particular to assess to what extent the evolution processes and Geomorphic Transport Laws that have been proposed and validated for soil mantled hillslopes are transferable to these settings.

The purpose of this study is to provide such quantitative insights into the dynamics of these landscapes and hillslopes through the combination of detailed morphological measurements with estimates of denudation based on in situ-produced cosmogenic nuclides inventories. We focused on the carbonate ranges of Provence in South-Eastern France which provide an ideal setting for such investigations. In particular we test if the fundamental relationship between surface curvature and denudation, which is often considered diagnostic of diffusive transport over regolith-mantled hillslopes, holds in these type of environments. We observe a two-stage evolution, with first a linear increase of denudation rates with hilltop curvature, as predicted by linear diffusion transport theory, and then a plateau where denudation is almost constant despite increasing curvature. We interpret this transition as the consequence of a limit in the ability of weathering processes to produce regolith fast enough to match hillslope transport capacity. We postulate that such evolution could lead to the decoupling of hillsopes evolution from the channels incising at their bottom and promote relief growth in carbonate landscapes.

In this paper, we first present the geological and geomorphological settings of the carbonate ranges of Western Provence, and in particular the Luberon massif where our investigation is focused. After presenting the methodology used to determine denudation rates from cosmogenic nuclides $\left({ }^{36} \mathrm{Cl}\right)$ measurements and hilltop curvature from the production of high resolution Digital Elevation Models, we introduce a simple 1D hillslope evolution model that allows combining the data obtained by both previous methods. At last, after reporting the main data and results we discuss the significance of the observed transition for the mechanisms of landscape evolution in carbonate domains. 


\section{Setting}

The sedimentary sequence of Western Provence is dominated by a thick Mesozoic platform carbonate series that was deformed during Cenozoic orogenesis. This led to the development of narrow ranges with significant relief, which provide an ideal setting to investigate the evolution of carbonate landscapes (figure 1A). We targeted an area of the Western Luberon mountain (Petit Luberon, figure $1 \mathrm{~B}$ ), a $600 \mathrm{~m}$ tall, E-trending and $20 \mathrm{~km}$-long range. It consists mostly of lower Cretaceous carbonates, with Urgonian facies reef limestones outcropping along the crest and northern flank of the range. The Luberon mountain was first uplifted during the Late Cretaceous and Early Eocene Pyrenean tectonic regime. Another major tectonic episode occurred between 10 and 6 Ma prior to the Messinian Salinity Crisis, and led to rejuvenation of the relief and incision [Molliex et al., 2011; Clauzon et al., 2011]. Denudation rates on weathering surfaces across south-eastern France ranges from 20 to $60 \mathrm{~mm} / \mathrm{ka}$ [Siame et al., 2004; Sadier et al., 2012; Molliex et al., 2013]. The lower bound corresponds to tectonically stable areas, whereas higher values are associated with actively uplifting surfaces.

We selected a specific area of the northern flank of the range, where several regularly spaced north-south ridges are connected with a summit surface (figure 1C). Their well-developed convex profiles suggest that slope-dependent transport is likely contributing to hillslope evolution (figure 2A-B). The low curvature summit surface is being progressively dismantled by regressive erosion along the main valleys draining the southern and northern flanks. This transient evolution is also reflected in the morphology of the ridges, which show significant increases in convexity with distance from the summit (figure 1C). Hillslopes become steeper away from the main crest and ultimately develop steep cliff faces associated with narrow gorges in the lower part of the range (figures 1 and 8 ).

The climate consists of a combination of Mediterranean and continental characteristics. Available records in Bonnieux (Altitude $250 \mathrm{~m}$ asl, figure 1B) over the 1981-2010 period indicate mean annual precipitation is $750 \mathrm{~mm} / \mathrm{yr}$, mean minimum annual temperature is $8^{\circ} \mathrm{C}\left(1^{\circ} \mathrm{C}\right.$ between December and February) and frost is present for 50 days per year. Our sites are located much higher on the crest of the range, between 600 and $700 \mathrm{~m}$ asl, and are directly exposed to the dominant wind (North-South blowing Mistral), suggesting that the conditions they experience are likely to be significantly colder. The ridges host sparse Mediterranean vegetation characterized by small shrubs and shallow grass. The surface is covered by thin but dense regolith $(<10 \mathrm{~cm}$ in most places) consisting of limestone clasts in the 1-10 cm size range and discontinuous shallow sandy to silty soil pockets (10 to $20 \mathrm{~cm}$ deep in most places) 
(figure 2). The dimension of these clasts make them transportable by biotic and frost wedging processes. Bedrock outcrops are widespread along these ridges and display a dense network of incipient dissolution features that contribute to clast production. This joint occurrence of meter-scale bedrock patches and thin discontinuous regolith is observed both on hilltops and hillslope flanks, with no clear downslope thinning or thickening trend for the regolith layer.

Bedrock and regolith observed along the crests have undergone both chemical weathering and physical disaggregation. Dissolution features are widespread on both bedrock outcrops and regolith clasts (figure 2E-F). Carbonate dissolution contributes to the progressive rounding of rock fragments and to the development and widening of a network of discontinuities in the rock mass (lapiaz) which in many cases produces transportable clasts. There is also widespread evidence of active fracture development (figure 2C), which appears to be related to thermal stresses and frost cracking but is also probably assisted by bioturbation and the development of the root network. We note that the production of clasts is also greatly facilitated by pre-existing tightly spaced fracture planes that are prevalent at most bedrock outcrops (figure 2D).

\section{Methods}

\subsection{Sampling strategy}

We focus on a single area within which relationships between denudation and morphology can be isolated under constant climate and lithology. Our sites are located on top of the ridges, where no regolith flux from above is contributing to the hillslope evolution. We use in situ-produced ${ }^{36} \mathrm{Cl}$ concentrations measured in both bedrock and regolith fragments $(1-10 \mathrm{~cm}$ size range) to quantify denudation rates at 12 sites. ${ }^{36} \mathrm{Cl}$ accumulates in near surface carbonates mainly due to nuclear reactions induced by cosmic ray interaction with Calcium. Hilltop curvature was determined using Digital Surface Models derived from pairs of high resolution aerial photographs at the same sites where we obtained estimates for denudation rates.

\subsection{Sample preparation and measurements}

Chlorine was extracted from our samples according to the standard protocol used in CEREGE [Schlagenhauf et al., 2010]. Bedrock and amalgamated clasts samples were crushed and sieved to extract the 250-1000 $\mu \mathrm{m}$ fraction. 
For each sample $\sim 50 \mathrm{~g}$ were loaded in Nalgene bottles and were submitted to three 5-hours cycles of leaching with MQ water and mechanical shaking. Further sample cleaning was done with a $\mathrm{HNO}_{3}$ (2M) leaching, resulting in the dissolution of $\sim 10 \%$ of the sample mass. The samples were then dried, weighted and spiked with $\sim 0.3 \mathrm{~g}$ of a $\mathrm{Cl}$ solution, with a concentration of $6.92 \pm 0.05 \mathrm{mg} / \mathrm{g}$ and ${ }^{35} \mathrm{Cl} /{ }^{37} \mathrm{Cl}$ and ${ }^{36} \mathrm{Cl} /{ }^{37} \mathrm{Cl}$ ratios of $917.8 \pm 4.4$ and $2.72 \pm 0.50 \times 10^{-12}$, respectively. Total dissolution of the carbonates was performed with $\mathrm{HNO}_{3}(2 \mathrm{M})$. The solution was filtered and the residues weighted. We then added $\sim 3 \mathrm{ml}$ of an $\mathrm{AgNO}_{3}$ solution $(100 \mathrm{mg} / \mathrm{g})$ for $\mathrm{AgCl}$ precipitation (3 days storage in the dark). The precipitate was dissolved in $\mathrm{NH}_{4} \mathrm{OH}$ (1:1) and $\sim 1 \mathrm{ml}$ of $\mathrm{Ba}\left(\mathrm{NO}_{3}\right)_{2}$ solution was added for sulfate precipitation. Filtering allowed to remove the $\mathrm{BaSO}_{4}$ precipitate, and final $\mathrm{AgCl}$ precipitation was achieved by adding $\sim 2 \mathrm{ml} \mathrm{NNO}_{3}$ (1:1). The precipitate was dried and stored in the dark until its final loading in targets for AMS measurements.

Measurements of the chlorine isotopic ratios were performed at the French AMS National Facility, ASTER, located at CEREGE in Aix-en-Provence [Merchel et al., 2008; Arnold et al., 2013]. A KNSTD1600 standard was used with assigned ratios for ${ }^{36} \mathrm{Cl} /{ }^{35} \mathrm{Cl},{ }^{36} \mathrm{Cl} /{ }^{37} \mathrm{Cl}$ and ${ }^{35} \mathrm{Cl} /{ }^{37} \mathrm{Cl}$ of $2.112 \times 10^{-12}$, $6.603 \times 10^{-12}$ and 3.127, respectively [Sharma et al., 1990; Fifield et al., 1990].

\subsection{Hilltop curvature measurements}

New algorithms in photogrammetry have allowed this technique to emerge as an alternative tool to Lidar in studies requiring very high resolution topography. Advances in computer vision and image analysis have generated innovative developments in photogrammetry through Structure-from-Motion (SfM) technique, which offers an automated method for the production of high-resolution models with standard cameras [e.g. James and Robson, 2012; Westoby et al., 2012]. This is achieved with calibrated cameras knowing the extrinsic orientation parameters. The identification of tie points between image pairs is done automatically and efficiently using the Scale Invariant Feature Transform (SIFT) algorithm, and the results are optimized and converted in an absolute reference frame using ground control points known precisely in a geodetic system. Then the transform from image to object geometry is performed by bundle rays block adjustment. It consists in a cost optimization function for the 3D structure and the viewing parameters. The outputs of the methods are primarily a dense 3D point cloud, and one can produce also a Digital Surface Model and an orthophotography by projecting the point cloud on a defined plane.

We used aerial photographs acquired by the Institut Géographique National 
(IGN), that were processed with Agisoft Photoscan Professional software suite to generate a high density point cloud. The sparse vegetation of this area allows a bare-Earth terrain model to be created, with only limited clipping of isolated bushes required. The point cloud was registered in RGF93, resulting in a typical density of $2.7 \pm 1.1$ points $/ \mathrm{m}^{2}$.

Calculations were performed on the point cloud in circular neighbourhoods centred around the sampling sites along the ridges. The size of this neighbourhood is based on the transition between the short wavelength signal associated with surface roughness and vegetation to the long wavelength signal of ridge and valley topography [Roering et al., 2010; Hurst et al., 2012], and in our case was set to $15 \mathrm{~m}$ (figure 4). Changing this radius in the 10-30 $m$ range or performing the calculation on the gridded Digital Elevation Model rather than on the point cloud slightly modified the values of the computed curvatures, but did not affect the general first-order trend in the dataset. We follow the approach of Hurst et al. [2012, 2013b] by fitting a quadratic surface to the neighbourhood around our sampling site,

$$
z(x, y)=a x^{2}+b y^{2}+c x y+d x+e y+f
$$

And curvature $C$ can be expressed from the coefficients of equation 1 as,

$$
C=2 a+2 b
$$

\subsection{Hillslope evolution model}

We develop a simple hillslope evolution model to understand the relations between denudation and curvature in this landscape. Geomorphic Transport Law (GTL)-based models of hillslope evolution have been extensively applied to the investigation of the behaviour of soil mantled landscapes in most situation underlain by silicate rich substrata [e.g. Anderson, 2002; Dietrich et al., 2003; Roering et al., 2004; Mudd and Furbish, 2004; Roering, 2008; Yoo et al., 2009; Pelletier and Perron, 2012; Pelletier et al., 2013]. We are well aware that carbonate landscapes have, in comparison, received far less attention, and that the formulation of some processes are not yet completely validated in such environments. With these limitations in mind, our purpose is not to perform an extensive parameter space exploration, but rather to test the implications of simple assumptions for processes operating at the scale of the hillslope.

Our model is based on a simple statement of conservation for the regolith cover (thickness $h$ ) transported downslope [e.g. Anderson, 2002]. The evolution of $h$ through time can be described by,

$$
\frac{\mathrm{d} h}{\mathrm{~d} t}=\frac{\rho_{b}}{\rho_{r}} \dot{W}+\frac{1}{\rho_{r}} \frac{\mathrm{d} q_{s}}{\mathrm{~d} x}-p_{d} h
$$


The first right hand term is a source associated with production of regolith from the underlying bedrock. We use a simple regolith production function based on an exponential decay (length scale $L_{0}$ ) of production with regolith thickness $(h)$ and a maximum production $E_{0}$ for exposed bedrock,

$$
\dot{W}=\frac{E_{0}}{\cos \theta} \exp \left(\frac{-h \cos \theta}{L_{0}}\right)
$$

The local slope is $\theta$, and the $\cos \theta$ maps vertical thickness into slope normal thickness. This formulation is based on extensive work in silicate-rich soilmantled landscapes [Heimsath et al., 1997, 2000], but we are aware that other formulations have been proposed [e.g. Small et al., 1999; Anderson, 2002; Carretier et al., 2014].

The second right hand term represents the regolith flux $q_{s}$ that evolves non linearly with topographic gradient $\nabla z$ [Roering et al., 1999, 2007; Roering, 2008], and is linearly dependent on regolith thickness [Pelletier et al., 2013],

$$
q_{s}=-\frac{K_{T} h \cos \theta \nabla z}{1-\left(\frac{\nabla z}{S c}\right)^{2}}
$$

$K_{T}$ is a transport coefficient $[\mathrm{L} / \mathrm{T}]$ and $S_{c}[\mathrm{~L} / \mathrm{L}]$ a critical slope gradient at which regolith flux goes to infinity.

Finally, we parametrize regolith dissolution during its downslope transport as a first-order kinetic process characterized by a constant rate $p_{d}$ of mass loss per units of mass and time.

\section{Data and results}

\subsection{Denudation rate measurements with ${ }^{36} \mathrm{Cl}$}

Denudation rates were calculated from ${ }^{36} \mathrm{Cl}$ concentrations, based on spatial scaling factors from Stone [2000] and using the approach and parameters of the procedure proposed by Schimmelpfennig et al. [2009] which relied on the Heisinger et al. [2002] muon schemes. The natural $\mathrm{Cl}$ concentration of all samples is lower than $10 \mathrm{ppm}$ and mostly between 4 and $2 \mathrm{ppm}$, the main production pathway for ${ }^{36} \mathrm{Cl}$ is thus through $\mathrm{Ca}$ spallation. All analytical results are provided in table 1.

Two process blanks were treated and measured along with our samples. They contained $0.123 \times 10^{6}$ and $0.068 \times 10^{6}$ atoms of ${ }^{36} \mathrm{Cl}$ which is two orders of magnitude lower than the $31.2 \pm 5.6 \times 10^{6}$ average value in our samples. They contained $0.052 \times 10^{18}$ and $0.095 \times 10^{18}$ atoms of natural chlorine which is at least one order of magnitude lower than the $3.11 \pm 1.59 \times 10^{18}$ average value 
in our samples.

Measured concentrations range from 0.6 to $1.410^{6}$ at/g, which corresponds to denudation rates in the $30-70 \mathrm{~mm} / \mathrm{ka}$ range and integrated time periods of 20 to $9 \mathrm{ka}$, respectively. The ${ }^{36} \mathrm{Cl}$ concentrations and their corresponding denudation rates are similar within $1 \sigma$ uncertainty for the bedrock and clasts samples, except at site 11 where the discrepancy is of about $10 \%$ (figure 3 ). We note variations in the Ca content of our samples of 30-40\%, with one sample as low as $21 \%$, which denote a significant dolomitic component at some sites (table 1). However, such variability in the rock composition does not seem to affect the observed denudation rates.

\subsection{Evolution of Hilltop curvature with denudation rates}

Curvatures values measured at our sites range from $\sim 0 \mathrm{~m}^{-1}$ at sites 6 and 12 to $\sim 0.05 \mathrm{~m}^{-1}$ at site 4 . Denudation rates progressively increase with hilltop curvature (figure 5). Starting from $30-40 \mathrm{~mm} / \mathrm{ka}$, a nearly linear trend is observed between curvature and denudation rate, consistent with transportlimited diffusive hillslope evolution. Such downslope displacement of the regolith is likely accomplished by bioturbation associated with root development [Hoffman and Anderson, 2014] and freeze-thaw cycles.

For hillslope curvature larger than $\sim 0.02 \mathrm{~m}^{-1}$ denudation rates do not increase substantially above $\sim 70 \mathrm{~mm} / \mathrm{ka}$, despite a two-fold increase in curvature. This plateau results from a behavioral change of the hillslope in which the rate of regolith production from the bedrock reaches its maximum value and cannot further increase, while curvature continues to evolve because of the ongoing hillslope relief development associated with progressive dissection and incision at the gully bottoms [e.g. Hurst et al., 2013a].

\subsection{Modelling results}

We define our reference model with a set of parameters that allows to reproduce the main characteristics of our dataset. We model the evolution of a $50 \mathrm{~m}$ long hillslope and impose, as a boundary condition, the lowering of the base level at a constant rate $(100 \mathrm{~mm} / \mathrm{ka})$ at the bottom of the hillslope, which corresponds to a progressive and continuous incision of the channels. We use a transport coefficient of $0.05 \mathrm{~m} / \mathrm{yr}$, which is not dimensionally equivalent to a diffusivity coefficient due to the linear dependence on regolith thickness of the transport law presented at equation 5 [Roering, 2008; Pelletier et al., 2013]. The critical hillslope gradient $S_{c}$ is 0.8 and the bedrock-toregolith density ratio of 1.5. The regolith production function (equation 4) is parametrized using a standard decrease length scale $L_{0}$ of $0.5 \mathrm{~m}$ and a 
maximum rate of surface lowering $E_{0}$ of $80 \mathrm{~mm} / \mathrm{ka}$. For an horizontal stable surface equation 3 is simply,

$$
\frac{\rho_{b}}{\rho_{r}} E_{0} \exp \left(\frac{-h}{L_{0}}\right)=p_{d} h
$$

This equation has no analytical solution, but can be numerically solved. Using a regolith dissolution rate of $0.01 \%$ per year produces a surface lowering of $\sim 30 \mathrm{~mm} / \mathrm{ka}$, close to observed values in the Luberon summit surface and elsewhere in peri-Mediterranean regions [Furlani et al., 2009; Ryb et al., 2014b,a].

The model displays a rapid increase of denudation at low curvature and then a slower evolution when reaching denudation rates of $60-80 \mathrm{~mm} / \mathrm{ka}$ (figure $6 \mathrm{~A})$, which is close to the maximum regolith production $E_{0}$ and represents a transition toward a situation where the evolution of the system is limited by the capacity of the hillslope to produce regolith. The associated topographic evolution (figure 6B) shows a progressive increase of relief with the development of hilltop curvature, while the base of the hillslope is continuously lowered.

The use of lower or higher transport coefficients results in less or more rapid increase of denudation with curvature during the early stage of the hillslope evolution, respectively (figure 6A). The differences in rates of change in denudation become narrower at latter stages when threshold processes are dominating the regolith transport. Variations in regolith dissolution rates are mostly influencing the rate of denudation of the initial flat surface, from almost no lowering for very low dissolution rate to rates up to $60 \mathrm{~mm} / \mathrm{ka}$ at dissolution equivalent to 4 times the reference value (figure $6 \mathrm{C}$ ). Finally, variations in the characteristic length controlling the dependence of the regolith production on depth (equation 4, figure 6D) are shifting the response curve toward slower or faster evolution for lower or higher values, respectively.

Again, we strongly argue against any over-interpretation of these modelling results, as we acknowledge that some model components such as the regolith production rule are still largely unconstrained in carbonate landscapes. Our approach is mainly heuristic and a thought experiment aimed at providing a general framework for the analysis of the behaviour of such hillslope. A systematic investigation of the values of specific parameters, beyond the simple sensitivity tests presented on figure 6 , is clearly not the objective of this model. 


\section{Discussion}

\subsection{Interpretation of denudation rates and controlling factors}

Our rates are within the range of denudation rate values reported in global compilations [Ryb et al., 2014a]. Over flat to low-convexity surfaces, the lower bound of $30 \mathrm{~mm} / \mathrm{ka}$ is slightly higher than other estimates on carbonate plateaus under Mediterranean climate [e.g. Furlani et al., 2009; Sadier et al., 2012]. The fact that ${ }^{36} \mathrm{Cl}$ concentrations (and hence denudation rates) are comparable for bedrock and amalgamated clasts sampled at identical locations has important implications for the evolution of the regolith cover of these ridges over the time period integrated by the method. We argue that this suggests the clasts are not remnants of a thicker soil or regolith that would have been recently eroded away due to a change in climate or land use, which would have produced lower concentrations in the buried and recently exhumed bedrock than the clasts. We therefore make the assumption that the present observed conditions can be extrapolated over at least the last $9 \mathrm{ka}$, which is the lowest reported integrated time period at our sites.

We could also consider an alternative possibility, where the clasts were previously located close to the interface between the bedrock and a thicker soil layer, that was eroded at some point during the Holocene [e.g. Fuchs, 2007]. Several lines of evidence are inconsistent with this hypothesis. First, our sites are located along hillcrests, with some of them presenting a high curvature (figure 2A) where the presence of thick soil is unlikely [e.g. Heimsath et al., 1997]. Second, such rapid transfer of soil from the hillslopes to the adjacent channels is likely to exceed the local transport capacity but we did not observe significant accumulation in the valley bottoms and hollows of the northern flank of the Petit Luberon. Finally, even if the clasts had been located at the bottom of a previous thicker soil cover, they would still be stratigraphically above the bedrock surface and vertically spread over a few tens of centimeters. The well constrained exponential decrease of spallogenic production of ${ }^{36} \mathrm{Cl}$ with depth would unambiguously lead to significantly lower ${ }^{36} \mathrm{Cl}$ concentrations in the bedrock and a corresponding systematic deviation below the 1:1 line in figure 3, which is not what we observe.

The limiting factors on carbonate dissolution have already been thoroughly investigated by Ryb et al. [2014b,a, 2015] across the Mediterranean and arid landscapes of Israel. Mean annual precipitation is $700 \mathrm{~mm} / \mathrm{yr}$ over the Luberon Mountains, where water availability is likely to be limiting chemical weathering processes [Ryb et al., 2014a]. This suggests that physical weathering develops in part because carbonate dissolution alone does not effectively 
limit relief development. We observe that both physical and chemical processes operate at our sites, in particular that dissolution develops small-scale karstic networks into the rock mass that then allow release of individual clasts (figures 2 and 7 ). We hypothesize that the maximum observed denudation corresponds to a limit in the capacity of the hillslope to dissolve the carbonate substrata and to produce regolith from bedrock. The coupling of physical and chemical processes does not allow us to unambiguously associate this limit to one type of weathering or another. This maximum value of $\sim 70 \mathrm{~mm} / \mathrm{ka}$ is relative to the specific climatic and lithological conditions at our sites, and for example, higher precipitation would probably increase this limit. In terms of hillslope-scale evolution, this behavioral change corresponds to a transition from a transport-limited to a weathering-limited regime. While we have not carried a quantitative investigation of this parameter, it appears that bedrock exposures are significantly more widespread at the high curvature sites 1 and 4, when compared with other surveyed locations.

\subsection{Regolith production and transport processes}

The hillslope evolution model generally reproduces the first-order evolution of curvature and denudation observed at the field sites, and in particular the two-stages evolution, with a near-stabilization of denudation at high curvature (figure 6). In the model, the presence of this limit is a direct consequence of the existence of maximum regolith production $E_{0}$ in equation 4 . We postulate that the evolution observed in our cosmogenic and topographic observations is the manifestation of underlying processes presenting a similar behaviour with respect to the evolution of the hillslope and regolith layer. While the actual nature of these processes is debated, it can be proposed that they are characterised by a limit corresponding to the maximum rate at which they can operate to lower the bedrock and produce regolith elements. Field observations in another carbonate massif in Western Provence (Nerthe range, figure 1A) provide some clues on the evolution of the shallow bedrock level (figure 7). We observe a transition in the degree of fracturing of the bedrock over the first meter below the surface. The uppermost part of the section displays a high fracture density which corresponds to the production of individual clasts in the $1-10 \mathrm{~cm}$ size range, that will be the main constituents of the regolith. Deeper in the section (20-30 cm below the surface) the spacing between fractures increases, and the bedrock appears to have been through a lesser degree of mechanical weathering. Closer views confirm that chemical and mechanical processes are jointly operating to produce the clasts, as the fracture edges are significantly smoothed by dissolution (figure 7B-C). These observations suggest that the processes that drive the fractur- 
ing of the bedrock (freeze-thaw cycles, biological agents) are only efficiently operating over a limited subsurface layer $(<1 \mathrm{~m})$ [Anderson et al., 2013]. Previous studies have shown that, in steady-state transport-limited landscapes dominated by linear slope-dependant regolith transport, the ratio between curvature and regolith production represents the efficiency of hillslope transport which is dimensionally equivalent to a diffusivity coefficient [e.g. Anderson, 2002]. The apparent diffusion coefficient associated with the trend in our data is $\sim 0.002 \mathrm{~m}^{2} / \mathrm{yr}$. This value is in the lower range of the global compilation by Hurst et al. [2013b], but is consistent for the observed precipitation at our sites and significantly higher than values in arid environments. It is also one order of magnitude lower than values determined for the soilmantled Mediterranean landscape of the Gabilan Mesa in Central California [Roering et al., 2007; Perron et al., 2012] and suggests that processes responsible for the mobilization of this coarse regolith are significantly less efficient than creep acting on a thick soil layer [McKean et al., 1993]. The contrast between the incised flanks and the flat summit surface (figure 8) points to a transient evolution of the range and probably implies some degree of deviation from steady-state for the hillslopes. However, in the initial stages of their evolution (curvatures $<0.02 \mathrm{~m}^{-1}$ ), the near linear relationship between curvature and denudation strongly support the idea that hillslopes are closely following channel incision at their bottom and remain close to steady-state. We note that the non-linear transport rule used in our modelling implies a much thinner regolith cover on the hillslope flank than on the hilltop when approaching the critical angle, which is not what we observed in in the field. Such discrepancy suggests that this non-linear formulation is not adequately capturing some aspects of regolith transport in this kind of environments.

The limestone clasts produced by chemical and mechanical bedrock weathering are incorporated into the mobile regolith layer and then progressively transported downslope. Using the $0.01 \% / \mathrm{yr}$ dissolution factor proposed above yields a characteristic time for the dissolution of $50 \%$ of clast mass of $\tau \simeq 7 \mathrm{ka}$. Such survival over the $10 \mathrm{ka}$ time-scale suggests that individual clasts produced at the hilltop are effectively moved away and transferred to the adjacent slopes over their life time.

\subsection{Implications for relief evolution in carbonate land- scapes}

Our results have important implications for landscape evolution in carbonatedominated settings, as they illustrate an abrupt limit of weathering processes to produce clasts and to lower the hillslope at a pace that matches the local 
base level fall. Such limitation of weathering below $\sim 70 \mathrm{~mm} / \mathrm{ka}$ may prevent the hillslope/channel system from reaching an equilibrium shape and lead to an increase in hillslope relief. We observe such transient evolution in our study area where the lower parts of the range display near-threshold hillslope angles and high local relief, whereas the low-relief summit area is dominated by continuous slope-dependent hillslope evolution processes (figure 8). At a global scale we note that Mediterranean landscapes often display high local relief at 1-10 km wavelengths, with common occurrence of prominent limestone cliffs up to several hundred meters high. Our observations in the Luberon Mountains suggest that such relief could be a consequence of the inability of local weathering processes operating at the hillslope scale to keep pace with the dissection of topography by the fluvial network.

Ryb et al. [2013] report a significant change in landscape dynamics in the Judea Hills of Israel occurring around the mid-Pleistocene, from a situation where active landsliding was the dominant denudation process, toward hillslopes controlled by largely slope-independent dissolution. They interpret the present-day landscape as mostly inactive in terms of mechanical and gravity driven processes with long-wavelength features mostly inherited from the previous stage. The landscape of the northern flank of the Luberon mountain is in a transient state and dynamically adjusting during its evolution and we do not observe characteristics features of remnant topography such as large knickpoints or massive alluvial and colluvial deposits. The contrast between the near threshold hillslopes and cliffs of the lower part of the range and our studied area near the summit surface (figure 8) is a manifestation of the transition from a landscape dominated by diffusion dominated processes, toward a regime where hillslope failure and rapid mass movement assume a larger role in landscape evolution (figure 1C). We consider both parts to be active, and to represent two distinct stages in a progressive transient evolution of the range.

\section{Conclusions}

We have documented denudation across a carbonate range of South-Eastern France. Flat surfaces that are unaffected by gravity driven processes lower at $30-40 \mathrm{~mm} / \mathrm{ka}$, which is consistent with other observations on similar surfaces in peri-Mediterranean regions. While investigations of the relationship between hillslope convexity and denudation are almost as old as Geomorphology [Gilbert, 1909] and central to many hillslope evolution models, there is currently only a limited number of studies which document their co-evolution, and in particular the linear relationship we observe on figure 5 . 
For our highest curvature sites we observe that denudation reaches a plateau at $\sim 60-70 \mathrm{~mm} / \mathrm{ka}$, which we interpret as a transition from transport-limited to weathering-limited evolution. Such change in behavior may promote the development of high local relief in Mediterranean landscapes as hillslopes become unable to match the imposed pace of base level lowering. Further investigations will attempt to address the dependence of the pattern we observe on figure 5 to different climatic settings in terms of precipitation and temperature.

\section{Acknowledgments}

This study was supported by the ECCOREV research federation and the Cashima Research Project (funded by the CEA Cadarache and ITER Organisation). We thank the Parc Naturel Régional du Luberon and the Office National des Forêts (ONF) for facilitating access to our field sites. The ${ }^{36} \mathrm{Cl}$ measurements were performed at the ASTER AMS national facility (CEREGE, Aix en Provence) which is supported by the INSU/CNRS, the ANR through the "Projets thématiques d'excellence" program for the "Equipements d'excellence" ASTER-CEREGE action, IRD and CEA. Simon Mudd, Bob Anderson, George Hilley and an anonymous reviewer are acknowledged for insightful comments on this manuscript. 


\section{References}

Anderson, R. S. (2002). Modeling the tor-dotted crests, bedrock edges, and parabolic profiles of high alpine surfaces of the Wind River Range, Wyoming. Geomorphology, 46(1-2):35-58.

Anderson, R. S., Anderson, S. P., and Tucker, G. E. (2013). Rock damage and regolith transport by frost: an example of climate modulation of the geomorphology of the critical zone. Earth Surface Processes and Landforms, 38(3):299-316.

Arnold, M., Aumaître, G., Bourlès, D. L., Keddadouche, K., Braucher, R., Finkel, R. C., Nottoli, E., Benedetti, L., and Merchel, S. (2013). The French accelerator mass spectrometry facility ASTER after 4years: Status and recent developments on 36Cl and 129I. Nuclear Instruments and Methods in Physics Research Section B: Beam Interactions with Materials and Atoms, 294:24-28.

Carretier, S., Goddéris, Y., Delannoy, T., and Rouby, D. (2014). Mean bedrock-to-saprolite conversion and erosion rates during mountain growth and decline. Geomorphology, 209:39-52.

Clauzon, G., Fleury, T. J., Bellier, O., Molliex, S., Mocochain, L., and Aguilar, J. P. (2011). Morphostructural evolution of the Luberon since the Miocene (SE France). Bulletin de la Societe Geologique de France, 182(2):95-110.

Culling, W. E. H. (1960). Analytical Theory of Erosion. The Journal of Geology, 68(3):336-344.

Dietrich, W. E., Bellugi, D. G., Sklar, L. S., Stock, J. D., Heimsath, A. M., and Roering, J. J. (2003). Geomorphic transport laws for predicting landscape form and dynamics. In Wilcock, P. R. and Iverson, R. M., editors, Prediction in Geomorphology, volume 135 of Geophysical Monograph Series, pages 103-132. American Geophysical Union, Washington, D. C.

Fifield, L., Ophel, T., Allan, G., Bird, J., and Davie, R. (1990). Accelerator mass spectrometry at the Australian National University's 14UD accelerator: experience and developments. Nuclear Instruments and Methods in Physics Research Section B: Beam Interactions with Materials and Atoms, 52(3-4):233-237. 
Foster, M. A., Anderson, R. S., Wyshnytzky, C. E., Ouimet, W. B., and Dethier, D. P. (2015). Hillslope lowering rates and mobile-regolith residence times from in situ and meteoric 10Be analysis, Boulder Creek Critical Zone Observatory, Colorado. Geological Society of America Bulletin, 127(5):862-878.

Fuchs, M. (2007). An assessment of human versus climatic impacts on Holocene soil erosion in NE Peloponnese, Greece. Quaternary Research, 67(3):349-356.

Furlani, S., Cucchi, F., Forti, F., and Rossi, A. (2009). Comparison between coastal and inland Karst limestone lowering rates in the northeastern Adriatic Region (Italy and Croatia). Geomorphology, 104(1):73-81.

Gilbert, G. K. (1909). The convexity of hilltops. The Journal of Geology, $17(4): 344-350$.

Heimsath, A. M., Chappell, J., Dietrich, W. E., Nishiizumi, K., and Finkel, R. C. (2000). Soil production on a retreating escarpment in southeastern Australia. Geology, 28(9):787-790.

Heimsath, A. M., Dietrich, W. E., Nishiizumi, K., and Finkel, R. C. (1997). The soil production function and landscape equilibrium. Nature, 388(6640):358-361.

Heisinger, B., Lal, D., Jull, A., Kubik, P., Ivy-Ochs, S., Knie, K., and Nolte, E. (2002). Production of selected cosmogenic radionuclides by muons: 2 . Capture of negative muons. Earth and Planetary Science Letters, 200(34):357-369.

Hoffman, B. S. S. and Anderson, R. S. (2014). Tree root mounds and their role in transporting soil on forested landscapes. Earth Surface Processes and Landforms, 39(6):711-722.

Hurst, M. D., Mudd, S. M., Attal, M., and Hilley, G. (2013a). Hillslopes record the growth and decay of landscapes. Science, 341(6148):868-871.

Hurst, M. D., Mudd, S. M., Walcott, R., Attal, M., and Yoo, K. (2012). Using hilltop curvature to derive the spatial distribution of erosion rates. Journal of Geophysical Research, 117(F2):F02017.

Hurst, M. D., Mudd, S. M., Yoo, K., Attal, M., and Walcott, R. (2013b). Influence of lithology on hillslope morphology and response to tectonic forcing in the northern Sierra Nevada of California. Journal of Geophysical Research: Earth Surface, 118(2):832-851. 
James, M. R. and Robson, S. (2012). Straightforward reconstruction of 3D surfaces and topography with a camera: Accuracy and geoscience application. Journal of Geophysical Research, 117(F3):F03017.

Johnstone, S. A. and Hilley, G. E. (2015). Lithologic control on the form of soil-mantled hillslopes. Geology, 43(1):83-86.

McKean, J. A., Dietrich, W. E., Finkel, R. C., Southon, J. R., and Caffee, M. W. (1993). Quantification of soil production and downslope creep rates from cosmogenic 10Be accumulations on a hillslope profile. Geology, $21(4): 343-346$.

Merchel, S., Arnold, M., Aumaître, G., Benedetti, L., Bourlès, D., Braucher, R., Alfimov, V., Freeman, S., Steier, P., and Wallner, A. (2008). Towards more precise $10 \mathrm{Be}$ and $36 \mathrm{Cl}$ data from measurements at the 10-14 level: Influence of sample preparation. Nuclear Instruments and Methods in Physics Research Section B: Beam Interactions with Materials and Atoms, 266(22):4921-4926.

Molliex, S., Bellier, O., Terrier, M., Lamarche, J., Martelet, G., and Espurt, N. (2011). Tectonic and sedimentary inheritance on the structural framework of Provence (SE France): Importance of the Salon-Cavaillon fault. Tectonophysics, 501(1-4):1-16.

Molliex, S., Siame, L. L., Bourlès, D. L., Bellier, O., Braucher, R., and Clauzon, G. (2013). Quaternary evolution of a large alluvial fan in a periglacial setting (Crau Plain, SE France) constrained by terrestrial cosmogenic nuclide (10Be). Geomorphology, 195(null):45-52.

Mudd, S. M. and Furbish, D. J. (2004). Influence of chemical denudation on hillslope morphology. Journal of Geophysical Research, 109(F2):F02001.

Pelletier, J. D., Barron-Gafford, G. a., Breshears, D. D., Brooks, P. D., Chorover, J., Durcik, M., Harman, C. J., Huxman, T. E., Lohse, K. a., Lybrand, R., Meixner, T., McIntosh, J. C., Papuga, S. a., Rasmussen, C., Schaap, M., Swetnam, T. L., and Troch, P. a. (2013). Coevolution of nonlinear trends in vegetation, soils, and topography with elevation and slope aspect: A case study in the sky islands of southern Arizona. Journal of Geophysical Research: Earth Surface, 118(2):741-758.

Pelletier, J. D. and Perron, J. T. (2012). Analytic solution for the morphology of a soil-mantled valley undergoing steady headward growth: Validation using case studies in southeastern Arizona. Journal of Geophysical Research: Earth Surface, 117(1):1-11. 
Perron, J. T., Kirchner, J. W., and Dietrich, W. E. (2008). Spectral signatures of characteristic spatial scales and nonfractal structure in landscapes. Journal of Geophysical Research, 113(F4):F04003.

Perron, J. T., Richardson, P. W., Ferrier, K. L., and Lapôtre, M. (2012). The root of branching river networks. Nature, 492(7427):100-103.

Roering, J. J. (2008). How well can hillslope evolution models "explain" topography? Simulating soil transport and production with high-resolution topographic data. Geological Society of America Bulletin, 120(9-10):12481262

Roering, J. J., Almond, P., Tonkin, P., and McKean, J. (2004). Constraining climatic controls on hillslope dynamics using a coupled model for the transport of soil and tracers: Application to loess-mantled hillslopes, South Island, New Zealand. Journal of Geophysical Research, 109(F1).

Roering, J. J., Kirchner, J. W., and Dietrich, W. E. (1999). Evidence for nonlinear, diffusive sediment transport on hillslopes and implications for landscape morphology. Water Resources Research, 35(3):853-870.

Roering, J. J., Marshall, J., Booth, A. M., Mort, M., and Jin, Q. (2010). Evidence for biotic controls on topography and soil production. Earth and Planetary Science Letters, 298(1-2):183-190.

Roering, J. J., Perron, J. T., and Kirchner, J. W. (2007). Functional relationships between denudation and hillslope form and relief. Earth and Planetary Science Letters, 264(1-2):245-258.

Ryb, U., Matmon, A., Erel, Y., Haviv, I., Benedetti, L., and Hidy, A. (2014a). Styles and rates of long-term denudation in carbonate terrains under a Mediterranean to hyper-arid climatic gradient. Earth and Planetary Science Letters, 406:142-152.

Ryb, U., Matmon, A., Erel, Y., Haviv, I., Katz, A., Starinsky, A., Angert, A., and Team, A. (2014b). Controls on denudation rates in tectonically stable Mediterranean carbonate terrain. Geological Society of America Bulletin, 126(3-4):553-568.

Ryb, U., Matmon, A., Haviv, I., and Benedetti, L. (2015). Exhumation and uplift coupled with precipitation along the western Dead Sea Rift margin. Geology, 43(6):483-486. 
Ryb, U., Matmon, A., Porat, N., and Katz, O. (2013). From mass-wasting to slope stabilization - putting constrains on a tectonically induced transition in slope erosion mode: A case study in the Judea Hills, Israel. Earth Surface Processes and Landforms, 38(6):551-560.

Sadier, B., Delannoy, J.-J., Benedetti, L., Bourlès, D. L., Jaillet, S., Geneste, J.-M., Lebatard, A.-E., and Arnold, M. (2012). Further constraints on the Chauvet cave artwork elaboration. Proceedings of the National Academy of Sciences of the United States of America, 109(21):8002-6.

Schimmelpfennig, I., Benedetti, L., Finkel, R., Pik, R., Blard, P.-H., Bourlès, D., Burnard, P., and Williams, A. (2009). Sources of in-situ 36Cl in basaltic rocks. Implications for calibration of production rates. Quaternary Geochronology, 4(6):441-461.

Schlagenhauf, A., Gaudemer, Y., Benedetti, L., Manighetti, I., Palumbo, L., Schimmelpfennig, I., Finkel, R., and Pou, K. (2010). Using in situ Chlorine-36 cosmonuclide to recover past earthquake histories on limestone normal fault scarps: A reappraisal of methodology and interpretations. Geophysical Journal International, 182:36-72.

Sharma, P., Kubik, P., Fehn, U., Gove, H., Nishiizumi, K., and Elmore, D. (1990). Development of 36Cl standards for AMS. Nuclear Instruments and Methods in Physics Research Section B: Beam Interactions with Materials and Atoms, 52(3-4):410-415.

Siame, L., Bellier, O., Braucher, R., Sébrier, M., Cushing, M., Bourlès, D., Hamelin, B., Baroux, E., de Voogd, B., Raisbeck, G., and Yiou, F. (2004). Local erosion rates versus active tectonics: cosmic ray exposure modelling in Provence (south-east France). Earth and Planetary Science Letters, $220(3-4): 345-364$.

Small, E. E., Anderson, R. S., and Hancock, G. S. (1999). Estimates of the rate of regolith production using $10 \mathrm{Be}$ and $26 \mathrm{Al}$ from an alpine hillslope. Geomorphology, 27(1-2):131-150.

Stone, J., Allan, G., Fifield, L., Evans, J., and Chivas, A. (1994). Limestone erosion measurements with cosmogenic chlorine-36 in calcite - preliminary results from Australia. Nuclear Instruments and Methods in Physics Research Section B: Beam Interactions with Materials and Atoms, 92(14):311-316.

Stone, J. O. (2000). Air pressure and cosmogenic isotope production. Journal of Geophysical Research, 105(B10):23753-23759. 
Westoby, M., Brasington, J., Glasser, N., Hambrey, M., and Reynolds, J. (2012). 'Structure-from-Motion' photogrammetry: A low-cost, effective tool for geoscience applications. Geomorphology, 179:300-314.

Yoo, K., Mudd, S. M., Sanderman, J., Amundson, R., and Blum, A. (2009). Spatial patterns and controls of soil chemical weathering rates along a transient hillslope. Earth and Planetary Science Letters, 288(1-2):184-193. 


\begin{tabular}{|c|c|c|c|c|c|c|c|c|}
\hline Site & Type & Latitude & Longitude & $\begin{array}{c}\text { Altitude } \\
\text { m }\end{array}$ & $\begin{array}{c}{\left[{ }^{36} \mathrm{Cl}\right]} \\
10^{6} \mathrm{at} / \mathrm{g}\end{array}$ & $\begin{array}{c}{[\mathrm{Ca}]} \\
\%\end{array}$ & $\begin{array}{l}{[\mathrm{Cl}]} \\
\text { ppm }\end{array}$ & $\begin{array}{c}\text { Denudation } \\
\mathrm{mm} / \mathrm{ka}\end{array}$ \\
\hline 1 & Clasts & 5.1587 & 43.8059 & 684 & $0.64 \pm 0.02$ & 31 & 2 & $71.9 \pm 7.5$ \\
\hline \multirow[t]{2}{*}{2} & Clasts & 5.1516 & 43.8059 & 706 & $0.85 \pm 0.02$ & 40 & 2 & $57.7 \pm 6.0$ \\
\hline & Bedrock & & & & $0.82 \pm 0.02$ & 40 & 3 & $60.2 \pm 6.3$ \\
\hline \multirow[t]{2}{*}{3} & Clasts & 5.1421 & 43.8143 & 707 & $0.71 \pm 0.02$ & 41 & 2 & $71.0 \pm 7.5$ \\
\hline & Bedrock & & & & $0.69 \pm 0.02$ & 34 & 2 & $69.1 \pm 7.2$ \\
\hline \multirow[t]{2}{*}{4} & Clasts & 5.1407 & 43.8163 & 694 & $0.59 \pm 0.02$ & 26 & 2 & $74.6 \pm 7.8$ \\
\hline & Bedrock & & & & $0.61 \pm 0.02$ & 30 & 2 & $74.6 \pm 7.8$ \\
\hline \multirow[t]{2}{*}{5} & Clasts & 5.1508 & 43.8111 & 672 & $0.66 \pm 0.02$ & 21 & 6 & $66.2 \pm 7.0$ \\
\hline & Bedrock & & & & $0.69 \pm 0.02$ & 31 & 7 & $67.7 \pm 7.1$ \\
\hline \multirow[t]{2}{*}{6} & Clasts & 5.1422 & 43.8140 & 687 & $0.97 \pm 0.03$ & 30 & 4 & $44.2 \pm 4.6$ \\
\hline & Bedrock & & & & $0.92 \pm 0.03$ & 31 & 4 & $47.6 \pm 4.9$ \\
\hline \multirow[t]{2}{*}{7} & Clasts & 5.1768 & 43.8095 & 680 & $1.01 \pm 0.03$ & 29 & 3 & $41.0 \pm 4.3$ \\
\hline & Bedrock & & & & $1.04 \pm 0.03$ & 35 & 4 & $42.6 \pm 4.4$ \\
\hline \multirow[t]{2}{*}{8} & Clasts & 5.1744 & 43.8092 & 622 & $0.63 \pm 0.02$ & 31 & 6 & $72.1 \pm 7.6$ \\
\hline & Bedrock & & & & $0.65 \pm 0.02$ & 33 & 7 & $71.1 \pm 7.4$ \\
\hline \multirow[t]{2}{*}{9} & Clasts & 5.1724 & 43.8082 & 624 & $0.84 \pm 0.03$ & 32 & 3 & $51.7 \pm 5.4$ \\
\hline & Bedrock & & & & $0.83 \pm 0.02$ & 33 & 3 & $52.9 \pm 5.5$ \\
\hline \multirow[t]{2}{*}{10} & Clasts & 5.1719 & 43.8091 & 625 & $0.76 \pm 0.02$ & 36 & 8 & $61.5 \pm 6.4$ \\
\hline & Bedrock & & & & $0.78 \pm 0.03$ & 34 & 10 & $60.4 \pm 6.4$ \\
\hline \multirow[t]{2}{*}{11} & Clasts & 5.1582 & 43.8084 & 663 & $0.65 \pm 0.02$ & 35 & 5 & $73.3 \pm 7.7$ \\
\hline & Bedrock & & & & $0.73 \pm 0.02$ & 32 & 7 & $64.1 \pm 6.7$ \\
\hline \multirow[t]{2}{*}{12} & Clasts & 5.231 & 43.797 & 660 & $1.40 \pm 0.08$ & 39 & 2 & $29.8 \pm 3.4$ \\
\hline & Bedrock & & & & $1.37 \pm 0.09$ & 38 & 2 & $30.9 \pm 3.7$ \\
\hline
\end{tabular}

Table 1: Analytical results for the samples processed in this study 

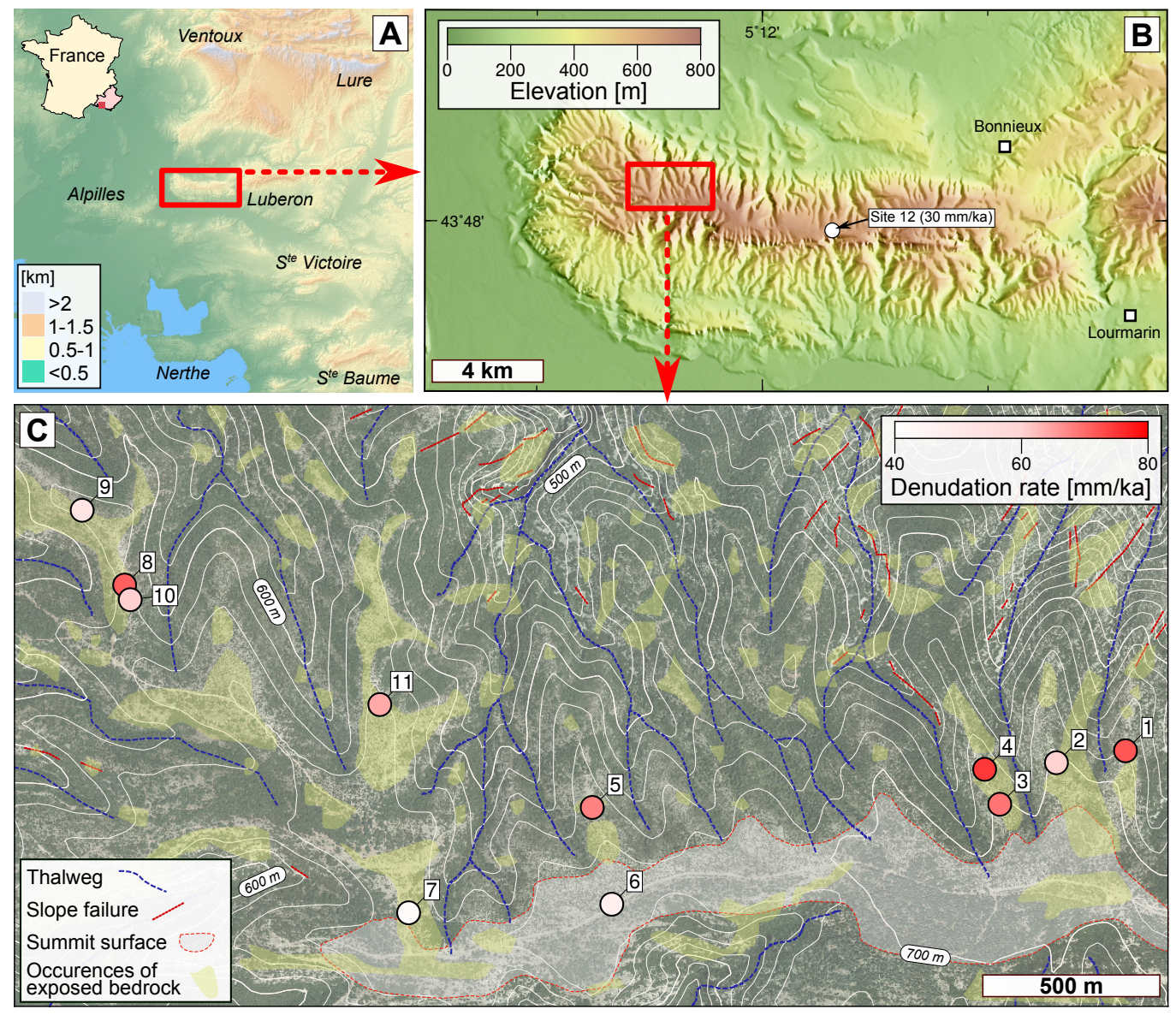

Figure 1: A - General situation map of the studied region (Provence, southeastern France), with the location of the main carbonate ranges. B - Situation map of the Petit Luberon mountain (IGN BDALTI DEM). C - Orthophotography of the main sampling area (IGN BDORTHO database), and main geomorphological features based on field surveys and air photos analysis. Samples are color coded according to their denudation rate. Thin white contour lines separation is $20 \mathrm{~m}$. Site 12 was sampled farther east, where the summit surface is the widest. 

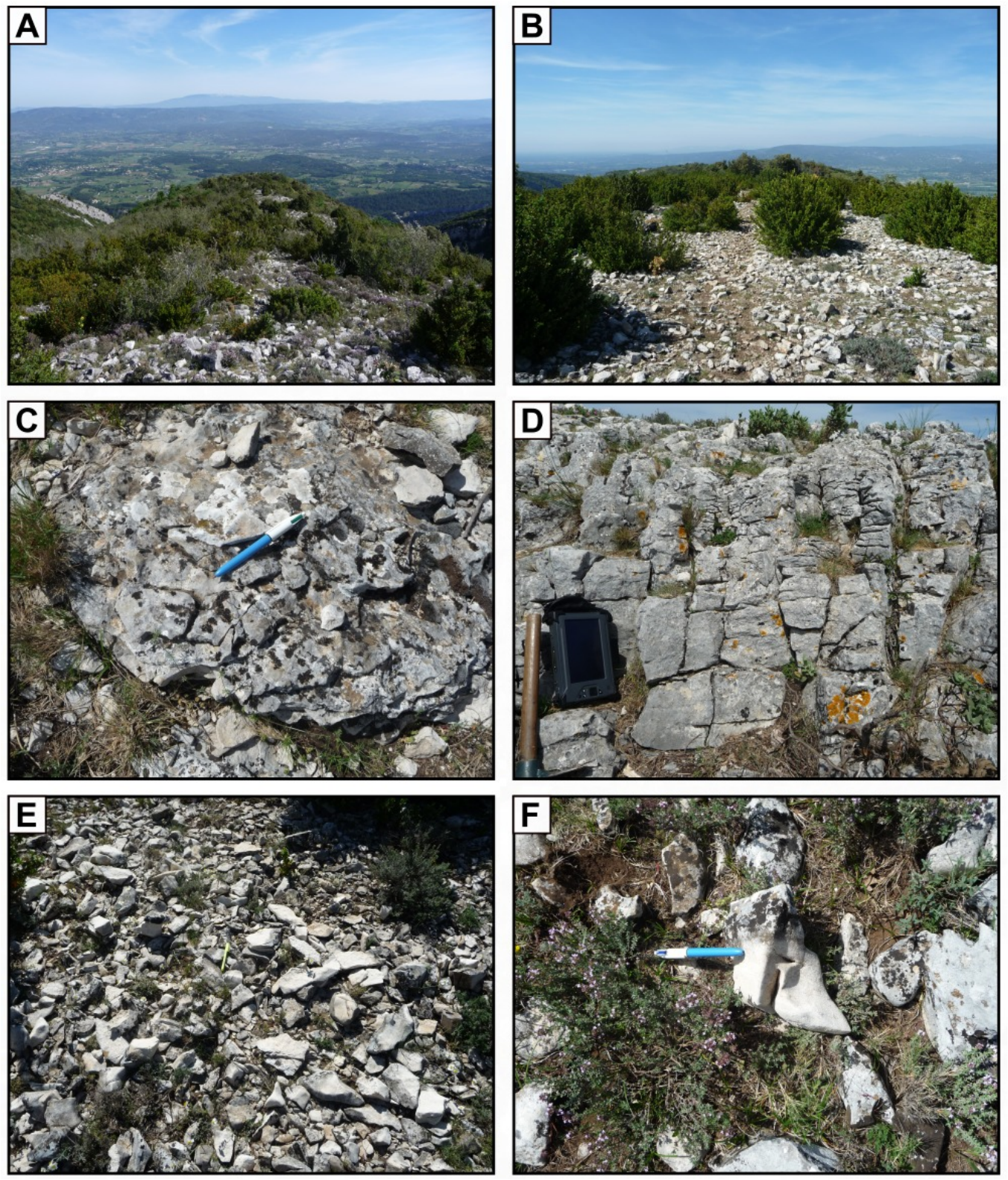

Figure 2: Field photographs illustrating geomorphological features of the Petit Luberon northern flank. A-B - Views along the ridge axis looking toward the north for sites 1 and 11, respectively. C - In-situ frost or bioturbation assisted fracturing contributing to the separation of individual clasts from the bedrock, observed at site 10. D - Pre-existing fractures and structural bedding contributing to the separation of individual clasts from the bedrock, observed at site 8. E - View of clasts pavements at the surface of site 2. F - Weathered and rounded clasts at the surface of site 8 , showing a clear distinction between the lower part of the clast embedded in the regolith (white, rounded and polished surface) and the upper part directly exposed at the surface (greyish surface partly20vered with lichens). 


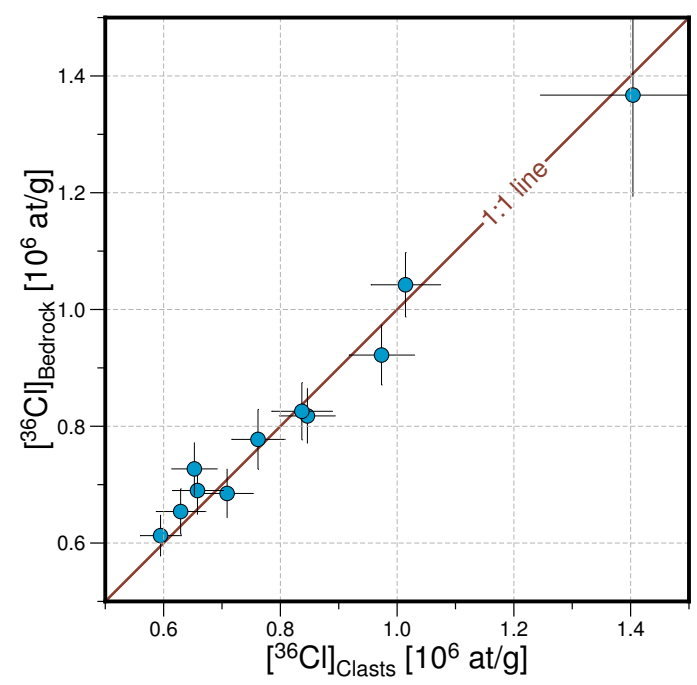

Figure 3: Comparison of ${ }^{36} \mathrm{Cl}$ concentrations in bedrock and amalgamated clasts samples at a same location.

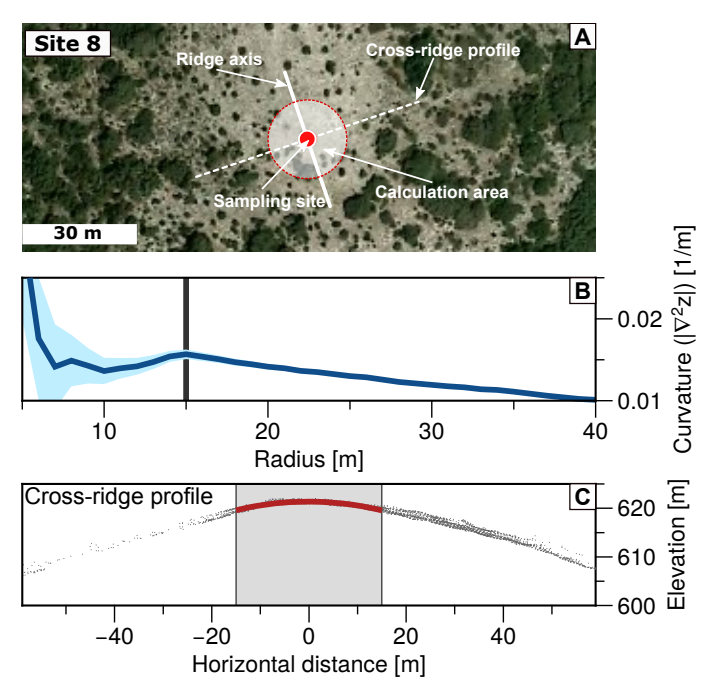

Figure 4: A - Aerial view of sampling site 8 (figure 1C), with sampling location and radius of calculation $(15 \mathrm{~m})$ for the curvature. B - Evolution of calculated curvature at site 8 with the radius of the calculation area. Light blue envelope indicates the $\pm 1 \sigma$ interval. Dark vertical line indicates the reference radius used in this study. C - Cross ridge topographic profile at site 8 (light gray points). Dark gray background indicates the calculation area for curvature corresponding to a $15 \mathrm{~m}$ radius around the sampling site. Solid thick red curve is quadratic fit through the data points. 


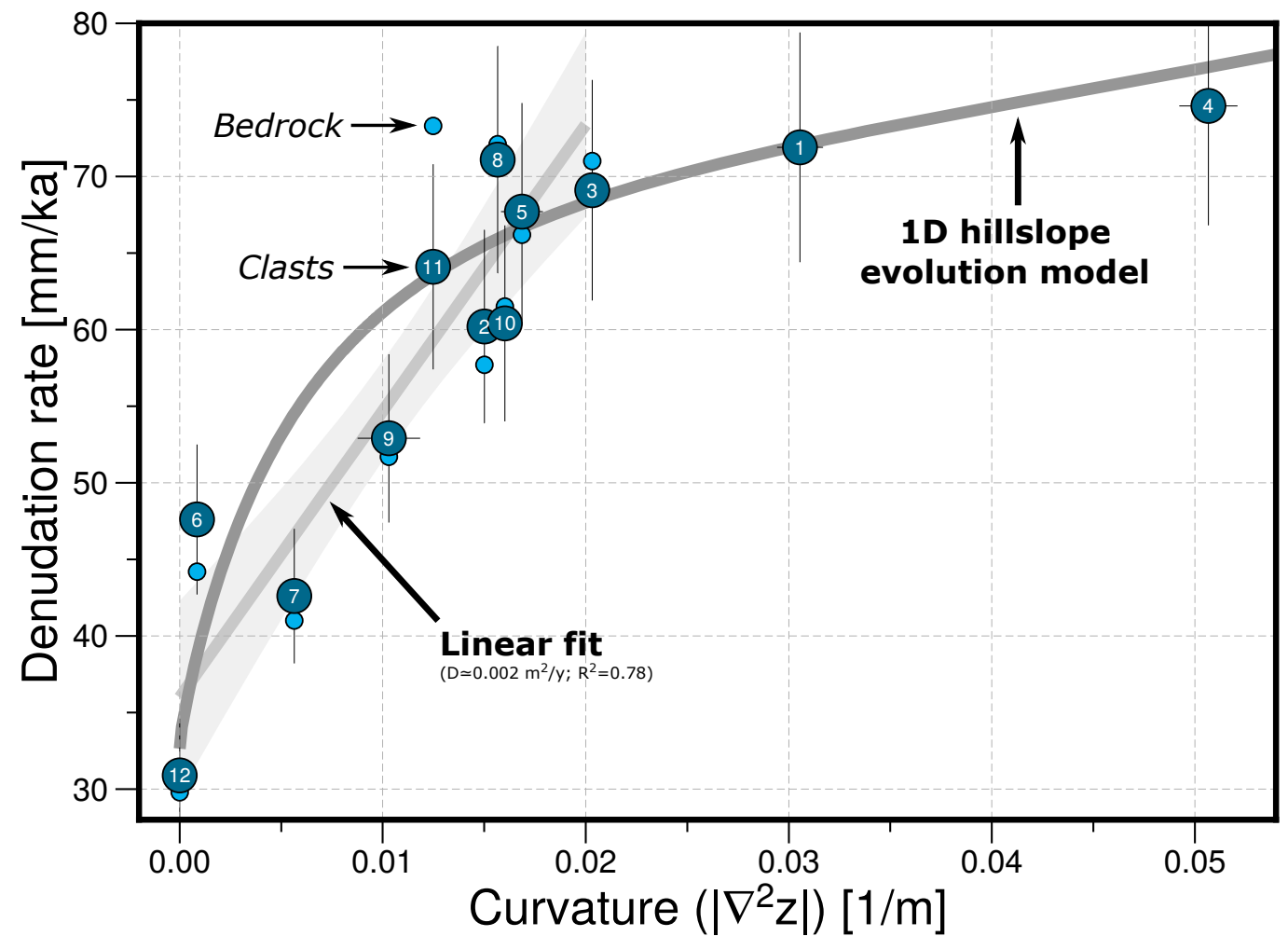

Figure 5: Denudation rates against hilltop curvature measured at our sampling sites. Large dark blue circles represent denudation rates measured from amalgamated clasts samples, whereas small light blue circles represent bedrock samples. The dark gray background curve is a prediction from a $1 \mathrm{D}$ diffusive hillslope evolution model (figure 6). The light gray line and envelope (95\% confidence) are a linear fit through the data for curvature $<0.02$ $\mathrm{m}^{-1}$. 

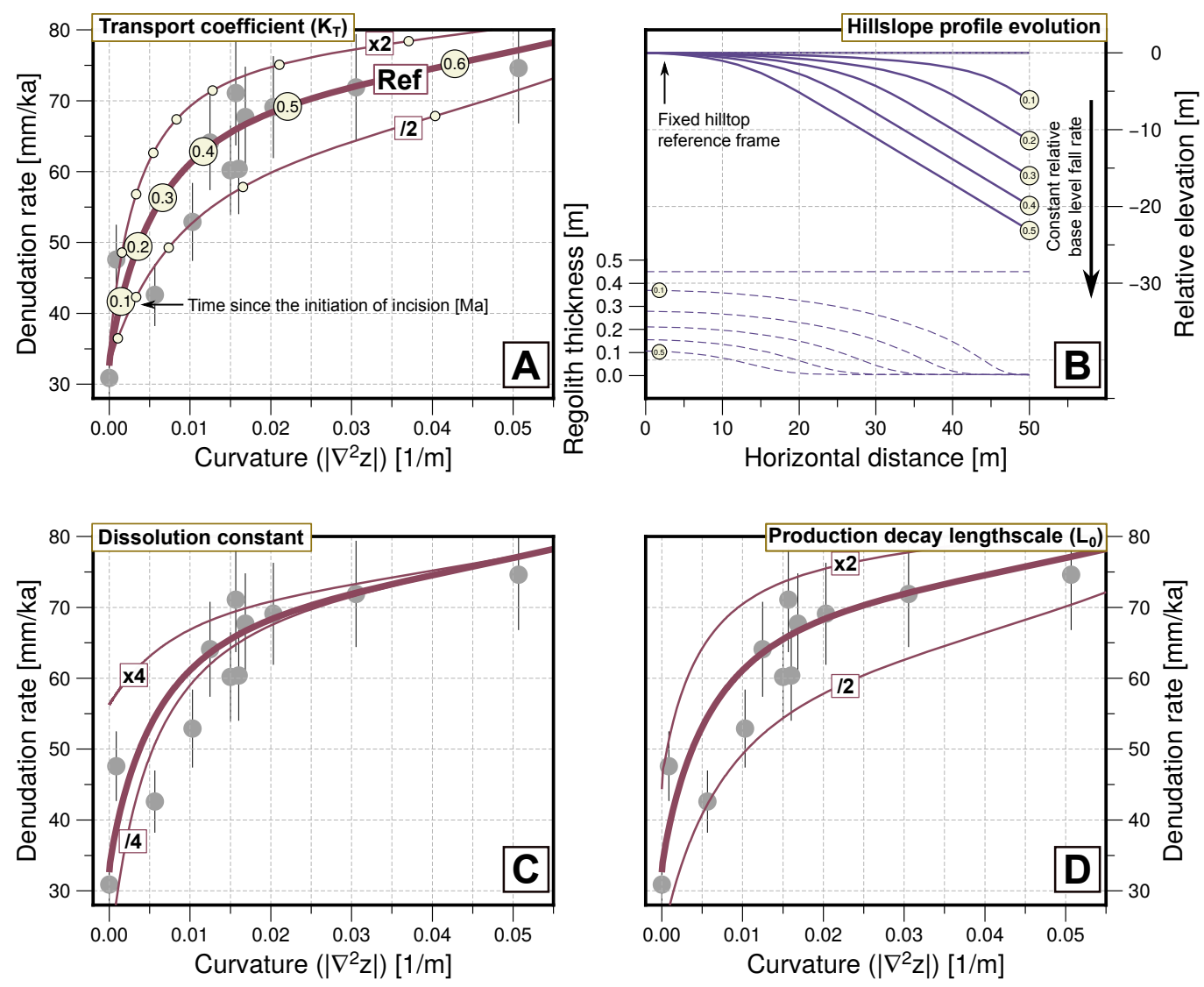

Figure 6: Modelling results. In all insets $\mathrm{A}, \mathrm{C}$ and $\mathrm{D}$ the thick line is the reference model. Grey circles in the background are the data points for the several sites presented in this study (figure 5). A - Test of the influence of 2 -fold variations for the transport coefficient $K_{T}$ (reference value $0.05 \mathrm{~m} / \mathrm{yr}$ ). Dots along the curves are indicating $100 \mathrm{kyr}$ time intervals since the initiation of channel incision at the base of the hillslope. B - Hillslope topography evolution (top) and regolith thickness (bottom) at the time intervals indicated on inset A (constant lowering rate of $100 \mathrm{~mm} / \mathrm{kyr}$ ). All topographic profiles have their hilltops aligned as a reference (hilltop surface are actually progressively lowered with respect to their initial position by dissolution). C - Test of the influence of 4-fold variations of the regolith dissolution rate (reference value $0.01 \% / \mathrm{yr}$ ). D - Test of the influence of 2 -fold variations of the e-folding decay length-scale of the regolith production function $L_{0}$ (reference value $0.5 \mathrm{~m}$ ). 

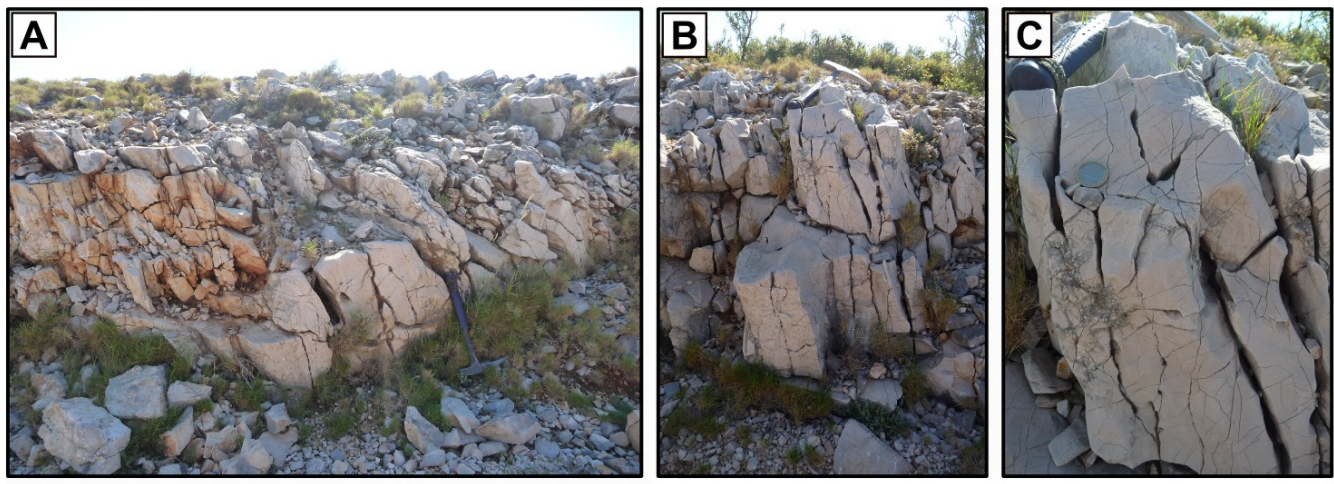

Figure 7: Field photographs of a bedrock section in the Nerthe massif (west of Marseille, N43.3437-E5.2397). See figure 1A for location. A - General view of the section showing the difference in bedrock fracturing with depth. B-C - Closer view illustrating the smoothing action of carbonate dissolution on fracture edges.

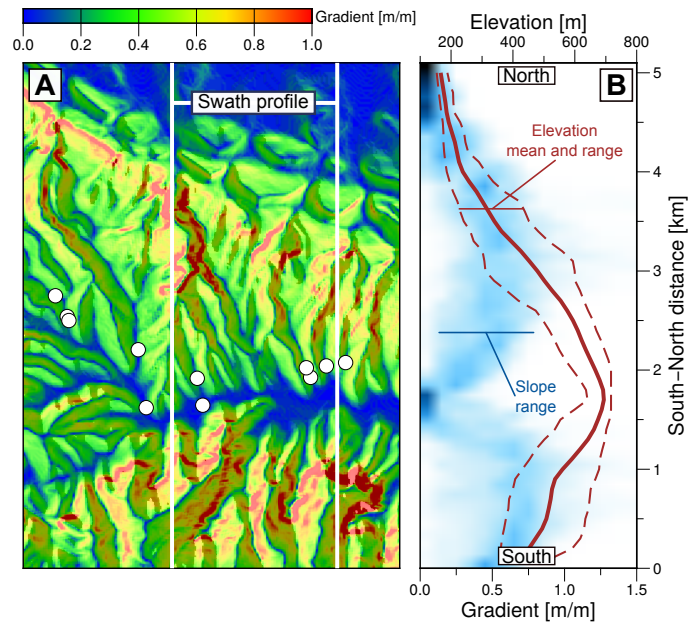

Figure 8: A - Topographic gradient map over the main sampling area. Vertical bars indicate the width of the swath profile presented on inset B. White circles are sampling sites (figure 1C). B - North-south profile across the northern flank of the Petit Luberon. Red solid and dashed lines are the mean and extreme values of elevation. Intensity of blue background indicates the frequency distribution of hillslope gradients. 